\title{
DE NUEVO SOBRE EL CONCEPTO DE ÓRGANO JURISDICCIONAL A EFECTOS DEL ARTÍCULO 267 TFUE: LOS SECRETARIOS JUDICIALES Y EL EXPEDIENTE DE JURA DE CUENTAS
}

Comentario de la sentencia TJUE de 16 de febrero de 2017, C-503/15, Margarit Panicello

PILAR CONCELLÓN FERNÁNDEZ ${ }^{1}$

concellonpilar@uniovi.es

Cómo citar/Citation

Concellón Fernández, P. (2017)

De nuevo sobre el concepto de órgano jurisdiccional a efectos del artículo 267 TFUE: los secretarios judiciales y el expediente de jura de cuentas. Comentario de la sentencia TJUE de 16 de febrero de 2017,

C-503/15, Margarit Panicello. Revista de Derecho Comunitario Europeo, 57, 709-733.

doi: https://doi.org/10.18042/cepc/rdce.57.10

\section{Resumen}

En la sentencia de 16 de febrero de 2017, que da respuesta a la primera cuestión prejudicial planteada por un secretario judicial español, el Tribunal de Justicia de la Unión Europea (TJUE) se pronuncia negativamente sobre la condición de ór-

1 Investigadora predoctoral de la Universidad de Oviedo. Este trabajo se adscribe al proyecto de investigación I+D+I del MINECO, ref. DER 2013-44950-R. La autora expresa su agradecimiento al secretario judicial Óscar Cabrera Galeano, remitente de la cuestión prejudicial cuyo comentario se ofrece a continuación, por facilitarle el acceso a todos los escritos del procedimiento. 
gano jurisdiccional nacional de esta figura en el expediente de jura de cuentas, por entender que la jurisdicción del órgano remitente no tiene carácter obligatorio, el procedimiento tiene carácter administrativo y al tramitarlo el secretario judicial no cumple la exigencia de independencia considerada en su aspecto externo. Adoptando una posición más restrictiva que en pronunciamientos anteriores, el TJUE se declara incompetente para pronunciarse sobre la petición de decisión prejudicial.

\title{
Palabras clave
}

Procedimiento prejudicial; art. 267 TFUE; secretario judicial; órgano jurisdiccional nacional; jurisdicción obligatoria; ejercicio de funciones judiciales; independencia; incompetencia del TJUE.

\section{ON THE CONCEPT OF A JURISDICTIONAL BODY FOR THE PURPOSES OF ARTICLE 267 TFEU: REGISTRARS AND THE ACTION FOR THE RECOVERY OF FEES. JUDGMENT OF THE COURT OF 16 FEBRUARY 2017, CASE C-503/15, MARGARIT PANICELLO}

\begin{abstract}
In its judgment of February 16th 2017, the Court of Justice declared itself incompetent to rule on the request for a preliminary ruling referred by a Spanish registrar. Taking a more restrictive position than in previous pronouncements, the Court of Justice understood that the registrars do not fulfill the requirement of independence considered in its external aspect. Furthermore, it declared that the procedure regarding an action for the recovery of fees was administrative in nature and it stated that the jurisdiction of the referring body was not mandatory.
\end{abstract}

\section{Keywords}

Article 267 TFEU; registrar; court or tribunal; compulsory jurisdiction; exercise of judicial functions; independence; lack of jurisdiction of the Court.

\section{LA NOTION DE JURIDICTION NATIONALE AUX FINS DE L'ARTICLE 267 TFUE: LES GREFFIERS ET L'ACTION EN PAIEMENT D'HONORAIRES. ARRET DE LA COUR DU 16 FEVRIER 2017, C-503/15, MARGARIT PANICELLO}

\section{Résumé}

Dans son arrêt du 16 Février 2017, qui répond au premier renvoi préjudiciel posée par un greffier du tribunal espagnol, la Cour rejette que les greffiers, dans le contexte de l'actions de paiement d'honoraires, soient habilités à adresser une demande de décision préjudicielle. La Cour adopte une position plus exigeante dans 
des déclarations antérieures en considérant que le greffier ne répond pas au critère d'indépendance et que l'action en paiement d'honoraires relève d'une procédure qui revêt un caractère administratif avec un caractère purement facultatif.

\section{Mot clés}

Renvoi préjudiciel; article 267 TFUE; Greffier; juridiction nationale; juridiction obligatoire; exercice de fonctions juridictionnelles; indépendance; incompétence de la cour. 


\section{SUMARIO}

I. INTRODUCCIÓN. II. LA CONTRIBUCIÓN DE LA PRÁCTICA ESPAÑOLA AL DESARROLLO DEL CONCEPTO DE "ÓRGANO JURISDICCIONAL». III. SOBRE EL PROCEDIMIENTO A QUO: LA NATURALEZA DEL EXPEDIENTE DE JURA DE CUENTAS. IV. EN EL ÁMBITO DEL PROCEDIMIENTO DE LA JURA DE CUENTAS ¿EL SECRETARIO JUDICIAL ES UN «ÓRGANO JURISDICCIONAL»?. 1. La posición del Estado español: una negativa firme. 2. La Comisión, a favor de la admisión. 3. La declaración de incompetencia por parte del Tribunal. 4. Las demás causas de inadmisibilidad que no se pudieron abordar. V. PARA CONCLUIR: EL CASUISMO CONTINÚA.

\section{INTRODUCCIÓN}

En la sentencia Margarit Panicello ${ }^{2}$, objeto de este comentario, el Tribunal de Justicia de la Unión Europea (TJUE) se enfrenta de nuevo a la necesidad de calificar al órgano que le plantea la cuestión prejudicial, con el fin de determinar si se trata de un órgano jurisdiccional nacional y por tanto si procede responder. No es la primera vez que tiene que hacerlo en relación con un órgano español, pero la novedad estriba en que en esta ocasión el planteamiento procede de un secretario judicial, actualmente denominado letrado de la Administración de Justicia tras la reforma introducida por la Ley Orgánica $7 / 2015^{3}$.

En línea con la posición negativa defendida por España y en contra de la mantenida por la abogada general ${ }^{4}$, el TJUE se decanta por declararse in-

2 Sentencia de 27 de febrero de 2017, Margarit Panicello, C-503/15, ECLI:EU:C:2017: 126.

3 Ley Orgánica 7/2015, de 21 de julio, por la que se modifica la Ley Orgánica 6/1985, de 1 de julio, del Poder Judicial (BOE núm. 174, de 22 de julio de 2015). No obstante, en este comentario mantendremos la denominación anterior debido a que así lo hacen tanto las conclusiones de la abogada general como la sentencia del TJUE.

4 Conclusiones de la abogada general Juliane Kokott en el asunto Margarit Panicello, C-503/15, ECLI:EU:C:2016:696. 
competente para pronunciarse por entender que no se reúnen algunos de los requisitos que componen la noción comunitaria de órgano jurisdiccional.

\section{LA CONTRIBUCIÓN DE LA PRÁCTICA ESPAÑOLA AL DESARROLLO DEL CONCEPTO DE «ÓRGANO JURISDICCIONAL»}

La vaguedad de los términos empleados en el art. 267 TFUE no ha supuesto ningún problema para los órganos considerados jurisdiccionales por nuestro ordenamiento, es decir, aquellos que forman parte de nuestro Poder Judicial. Así, solo dos meses después de su adhesión a la actual Unión Europea (UE), España planteaba de la mano del Tribunal Central de Trabajo su primera cuestión prejudicial ${ }^{5}$, a la que pronto se unieron muchas otras procedentes del resto de órdenes jurisdiccionales. Por contra, sí ha sido cuestionada la potestad prejudicial de otros órganos no incluidos en el Poder Judicial y que, sin embargo, desempeñaban aparentes competencias jurisdiccionales.

Este fue el caso del entonces Tribunal de Defensa de la Competencia (en adelante TDC), que mediante auto de 28 de enero de 1991 planteó, con arreglo al antiguo art. 177 TCEE, varias cuestiones prejudiciales. El TDC, creado por la Ley 110/1963, estaba dotado de los caracteres aparentemente necesarios para ser considerado como órgano jurisdiccional, esto es, origen legal, permanencia, jurisdicción obligatoria, procedimiento contradictorio y aplicación de normas jurídicas; sin embargo, pese a que en la misma ley también se indicaba que el TDC gozaría de plena y absoluta independencia en su función, este aspecto fue cuestionado. Por un lado, porque su cometido principal consistía en imponer las sanciones que previamente le proponía la Dirección General de Defensa de la Competencia; por otro, porque la misma ley que lo creaba $(110 / 1963)^{6}$ y la posterior $16 / 1989^{7}$, lo adscribían orgánicamente al «Ministerio competente en razón de la materia»", es decir, al Ministerio de Economía y Hacienda y, por último, porque «sus acuerdos definitivos en materia de imposición de multas son impugnables ante la jurisdicción

5 Sentencia de 29 de septiembre de 1987, Giménez Zaera C-126/86, ECLI:EU:C:1987: 395.

6 Ley 110/1963, de 20 de julio, de Represión de Prácticas Restrictivas de la Competencia (derogada por la Ley 16/1989).

7 Ley 16/1989, de 17 de julio, de Defensa de la Competencia (vigente hasta el 1 de septiembre de 2007).

8 Art. 20 Ley 16/1989. 
contencioso-administrativa ${ }^{9}$, lo que para algunos autores ${ }^{10}$ vendría a demostrar su naturaleza administrativa y no jurisdiccional.

A pesar de ello, el TJUE dio respuesta a las cuestiones planteadas por el $\mathrm{TDC}^{11}$ sin entrar a examinar su carácter jurisdiccional. Quien sí lo hizo fue el abogado general Jacobs. En sus conclusiones ${ }^{12}$, basándose en el auto de remisión del TDC, concluyó que no le cabía duda de que el TDC debía ser considerado un órgano jurisdiccional a efectos del art. 177 ya que el TDC gozaba de competencia privativa en determinadas materias, con arreglo a la legislación española, ejercía sus funciones con total independencia y sus miembros eran inamovibles.

Más polémica ha sido la consideración como órgano jurisdiccional nacional de los tribunales económico administrativos. Pese a que después de la adhesión de España a la UE varios tribunales económico administrativos se declararan incompetentes para presentar cuestiones prejudiciales ${ }^{13}$, en 1990 el Tribunal Económico Administrativo Central (en adelante TEAC), a través de su resolución de 29 de marzo de $1990^{14}$ y basándose en los criterios enumerados en la jurisprudencia del TJUE, se autoproclamó competente para realizar reenvíos prejudiciales. Un año después, y en coherencia a lo declarado en su resolución, el mismo TEAC planteó dos cuestiones prejudiciales. Sorprendentemente, en el asunto Diversinte ni el abogado general ni la propia sentencia del TJUE pusieron en duda la legitimación del TEAC para plantear cuestiones prejudiciales. Reconocieron implícitamente su carácter jurisdiccional y avalaron, por tanto, en contra de la opinión de la mayor

9 Art. 31 Ley 110/1963.

10 Rafael ILLESCAS ORTIZ, «Derecho de competencia: la competencia leal», en Guillermo J. JIMÉNEZ SÁNCHEZ, Derecho Mercantil, vol. 1, Ariel, Barcelona, 2003, pp. 699 a 708; Dámaso RUIZ-JARABO COLOMER, El Juez nacional como Juez Comunitario, Civitas, Madrid, 1993, pp. 80-82 y Francisco SOSA WAGNER, Jurisdicciones administrativas, Sevilla, 1977, pp. 102 y ss.

11 Sentencia de 16 de julio de 1992, C-67/91, ECLI:EU:C:1992:330.

12 Conclusiones presentadas el 10 de junio de 1992, C-67/91, ECLI:EU:C:1992:256.

13 A modo de ejemplo, la resolución de 15 de junio de 1989 del Tribunal Económico Administrativo Provincial de Madrid dice que «en tanto que los tribunales económico administrativos españoles se incardinan dentro de nuestro acervo legislativo tributario como dependientes orgánicamente de la Administración, y en concreto, del Ministerio de Economía y Hacienda, quedando, pues, al margen de cualquier consideración como órganos jurisdiccionales».

14 Resolución de 29 de marzo de 1990, publicada íntegramente en Noticias/C.E.E, año VI, núm. 69. 
parte de la doctrina ${ }^{15}$, su autoproclamación como órgano jurisdiccional a los efectos del actual art. 267 TFUE $^{16}$.

Años después de este asunto, mediante varias resoluciones recibidas en el TJUE el 14 de abril de 1998, el Tribunal Económico Administrativo Regional de Cataluña planteó una cuestión prejudicial relativa a la interpretación de la Sexta Directiva en materia de armonización de las legislaciones de los Estados miembros relativas a los impuestos sobre el volumen de negocios. En esta ocasión, el TJUE sí consideró necesario valorar si el órgano remitente era efectivamente un órgano jurisdiccional y a pesar de que en sus conclusiones el abogado general Saggio dejara patente que procedía albergar serias dudas sobre la independencia y el carácter contradictorio del procedimiento, el TJUE concluyó que el Tribunal Económico Administrativo Regional de Cataluña, órgano administrativo, no perteneciente al Poder Judicial español, era competente para plantear cuestión prejudicial ${ }^{17}$.

15 Ricardo ALONSO GARCÍA, «La noción de órgano jurisdiccional a los efectos de activar la cuestión prejudicial», en Carlos R. FERNÁNDEZ LIESA, Carlos J. MOREIRO GONZÁLEZ, Eduardo MENÉNDEZ REXACH, (dirs.), Homenaje a Dámaso Ruiz-Jarabo Colomer, Consejo General del Poder Judicial, Madrid, 2011, pp. 147166; Julio BANACLOCHE PALAO, «Los Tribunales Económico-Administrativos», Impuestos. Revista de doctrina. Legislación y Jurisprudencia, 2001-2, pp. 1-8; Manuel CIENFUEGOS MATEO, «La noción de órgano jurisdiccional de un Estado miembro ex art. 234 del tratado CE y su necesaria revisión», Gaceta Jurídica de la UE y de la Competencia, núm. 238, 2005, pp. 3-26; Eduardo GARCÍA DE ENTERRÍA, «Las competencias y el funcionamiento del Tribunal de Justicia de las Comunidades Europeas. Estudio Analítico de los recursos» en Eduardo GARCÍA DE ENTERRÍA., Julio D. GONZÁLEZ CAMPOS, y Santiago MUÑOZ MACHADO, Tratado de Derecho Comunitario europeo. Estudio sistemático desde el Derecho español, tomo I, Civitas, Madrid, 1986, p. 707; Dámaso RUIZ-JARABO COLOMER, El Juez nacional como Juez Comunitario, Civitas, Madrid, 1993, pp. 80-82; José Eugenio SORIANO GARCÍA, "El efecto directo de las Directivas: posiciones iniciales de nuestra jurisprudencia», Noticias CEE, núm. 52, 1989.

16 Sentencia del Tribunal de Justicia de 1 de abril de 1993, Diversinte y Iberlacta, C-260/91 y C-261/91, ECLI:EU:C:1993:136 y conclusiones del abogado general Gulmann ECLI:EU:C:1992:493.

17 Sentencia de 21 de marzo de 2000, Gabalfrisa y otros, C-110/98 a C-147/98, ECLI:EU:C:2000:145. Véase el reciente y detallado análisis de RODRÍGUEZ MEDAL sobre la competencia prejudicial de los tribunales económico-administrativos en Jaime RODRÍGUEZ MEDAL, "Concept of a Court or Tribunal under the Reference for a Preliminary Ruling: Who can Refer Questions to the Court of Justice of the EU?», European Journal of Legal Studies, vol. 8, núm. 1, 2015, pp. 122-125. 
Para Saggio, de las disposiciones que regulaban la composición y el funcionamiento de los TEAR no podía concluirse que los tribunales económico administrativos actuaran "con todas las garantías de independencia y de posición de tercero con respecto al poder ejecutivo" ya que el hecho de estar integrado orgánicamente en el Ministerio de Economía y Hacienda y que sus resoluciones fueran recurribles en todos los casos ante los órganos de la jurisdicción contencioso administrativa demostraban que la reclamación económico-administrativa ejercía la función típica de los recursos administrativos: «Dar a la Administración la oportunidad de dictar, también mediante un procedimiento contradictorio con los interesados, su decisión en justicia definitiva». ${ }^{18}$

No obstante, el TJUE consideró que la legislación española ${ }^{19}$ garantizaba la separación funcional entre los servicios de la administración tributaria responsables de la gestión, liquidación y recaudación, por una parte, y, por otra, de los tribunales económico administrativos, que resuelven las reclamaciones presentadas contra las decisiones de dichos servicios sin recibir instrucción alguna de la administración tributaria, lo que bastaba para conferirles «la cualidad de tercero en relación con los servicios que adoptaron la decisión objeto de la reclamación y la independencia necesaria para poder ser considerados órganos jurisdiccionales en el sentido del art. 177 del Tratado» ${ }^{20}$.

Otro de los órganos no pertenecientes al poder judicial, de naturaleza administrativa según nuestro ordenamiento estatal, al que el TJUE ha reconocido competencia prejudicial, es el Tribunal Català de Contractes del Sector Públic (en adelante TCCSP), órgano encargado de conocer los recursos especiales planteados contra las decisiones de adjudicación en materia de contratación pública en Cataluña y cuya jurisdicción es potestativa.

En su sentencia de 6 de octubre de $2015^{21}$, el TJUE solo entra a valorar los criterios de independencia y obligatoriedad de su jurisdicción, al entender que por lo que respecta a los criterios referentes al origen legal del órgano, a su permanencia, al carácter contradictorio del procedimiento y a la aplicación por parte del órgano de normas jurídicas, los autos en poder del TJUE no contenían dato alguno que permitiera poner en entredicho el carácter de órgano jurisdiccional del TCCSP.

18 Conclusiones del abogado general Antonio Saggio en el asunto Gabalfrisa, C-110/98, ECLI:EU:C:1999:489, punto 18.

19 Art. 90 de la Ley 230/1963.

20 Apdo. 40 de la Sentencia.

21 Sentencia de 6 de octubre de 2015, Consorci Sanitari del Maresme, C-203/14, ECLI:EU:C:2015:664. 
En cuanto al criterio de independencia, el TJUE considera que el TCCSP tiene la condición de tercero con respecto a la autoridad que adopta las decisiones recurridas ante él. Ello en base a que el TCCSP ejerce sus funciones con plena autonomía, sin estar sometido a ningún vínculo jerárquico o de subordinación $^{22}$, y que sus miembros son inamovibles y solo pueden ser cesados por alguna de las causas expresamente enumeradas en la normativa que los regula ${ }^{23}$.

Por lo que respecta al carácter obligatorio de su jurisdicción, el TJUE entiende que a pesar de que el recurrente en materia de contratación pública podía optar entre el recurso especial ante el TCCSP y el recurso contencioso administrativo, las resoluciones del TCCSP, cuya competencia no dependía de un acuerdo entre las partes, eran vinculantes para estas últimas y que en base a la práctica y puesto que los licitadores en los procedimientos de adjudicación de contratos públicos no interponían, como regla general, recurso contencioso administrativo sin haber planteado previamente un recurso especial ante el TCCSP, quedaba demostrado que los tribunales contencioso-administrativos intervenían como segunda instancia, de manera que la tarea de velar por el respeto del derecho de la UE en materia de contratos públicos en Cataluña correspondía en primer término al TCCSP. Lo que le llevó a concluir que el TCCSP cumplía con el criterio de carácter obligatorio de su jurisdicción ${ }^{24}$.

Pues bien, a esta práctica no siempre clara, se añade ahora la relativa a la competencia prejudicial de los secretarios judiciales. El 23 de septiembre y el 18 de noviembre de $2015^{25}$ tuvieron entrada en el Registro del Tribunal

22 A pesar de estar adscrito al Gobierno autonómico, en concreto a Presidencia (arts. 1 y 2 del Decreto 221/2013 de la Generalitat de Catalunya, de 3 de septiembre, DOGC, núm. 6454, de 5 de septiembre de 2013), el TJUE niega su dependencia.

23 Art. 8, apdo. 4, del Decreto 221/2013 de la Generalitat de Catalunya.

24 En este sentido Carlos JERICÓ ASÍN, «El derecho europeo reconoce que los tribunales administrativos de contratos tienen naturaleza jurisdiccional. STJUE, de 6 de octubre 2015, consorci sanitari del maresme, C-203/14 (TJCE 2015, 233)», Revista Aranzadi Doctrinal, núm. 1, 2016, pp. 205-207, y Ma Belén LÓPEZ DONAIRE, «Comentario a la sentencia del TJUE del 6 de octubre de 2015 Consorci Sanitari del Maresme (C-203/14) según el cual las administraciones públicas pueden participar en licitaciones, y pueden y deben ser admitidas en las listas oficiales de empresarios, proveedores o prestadores de servicios oficiales», Gabilex: Revista del Gabinete Jurídico de Castilla-La Mancha, núm. 4, 2015, pp. 171-176.

25 Asunto Margarit Panicello, C-503/15 y Martínez Roges C-609/15 respectivamente. Las dos cuestiones prejudiciales se planteaban en el marco de dos procedimientos de jura de cuentas sustanciados ante el mismo secretario judicial. El contenido de ambos decretos es prácticamente idéntico; no obstante, en el segundo decreto el remitente hacía 
de Justicia las dos primeras cuestiones prejudiciales planteadas por el mismo secretario judicial y sobre el mismo tema. En los escritos remitidos ${ }^{26}$, el secretario judicial plantea sus dudas sobre la compatibilidad de los procedimientos de jura de cuentas regulados en el derecho españo ${ }^{27}$ con las directivas relativas a la protección de los consumidores ${ }^{28}$. En su sentencia de 16 de febrero de 2017, el Tribunal de Justicia se pronuncia sobre su competencia para responder al primero de ellos, formulado en el contexto de un litigio sobre derechos de guarda y custodia sustanciado ante el Juzgado de Violencia sobre la Mujer de Terrassa, en el transcurso del cual el abogado Margarit Panicello inició expediente de jura de cuentas en reclamación de los honorarios devengados por su defendida, la Sra. Hernández Martínez.

\section{SOBRE EL PROCEDIMIENTO A QUO: LA NATURALEZA DEL EXPEDIENTE DE JURA DE CUENTAS}

El expediente de jura de cuentas ha sido definido por el Tribunal Constitucional español (TC) como «un procedimiento de naturaleza ejecutiva para

referencia a la reforma introducida por la Ley 42/2015 y a su nueva denominación como letrado de la Administración de Justicia. El 17 de febrero de 2017, la Secretaría del Tribunal de Justicia notificó al órgano jurisdiccional remitente la sentencia dictada en el asunto que nos ocupa, invitándolo a que indicara si, a la luz de dicha sentencia, deseaba mantener su segunda petición de decisión prejudicial. Mediante escrito de 11 de abril de 2017, el letrado de la Administración de Justicia informó al TJUE de que no deseaba mantener su segunda petición de decisión prejudicial y en base al art. 100 del Reglamento de Procedimiento del TJUE, el TJUE procedió a archivar el asunto.

La cuestión prejudicial en este caso es planteada mediante decreto, escrito procesal dictado por los secretarios judiciales con el fin de «admitir la demanda, poner término al procedimiento del que tenga atribuida exclusiva competencia, o cuando sea preciso o conveniente razonar su decisión» (art. 456.3 L.O.P.J.).

27 Arts. 34 y 35 de la Ley de Enjuiciamiento Civil. La jura de cuentas es un proceso especial que el ordenamiento jurídico español concede a los procuradores y abogados para el cobro de sus derechos y honorarios en relación a los juicios en los que intervengan. Como veremos, esto no excluye que estos profesionales puedan renunciar al uso de la cuenta jurada y reclamar sus honorarios en un proceso declarativo ordinario.

Directiva 93/13/CEE del Consejo, de 5 de abril de 1993, sobre las cláusulas abusivas en los contratos celebrados con consumidores y la Directiva 2005/29/CE del Parlamento Europeo y del Consejo de 11 de mayo de 2005 relativa a las prácticas comerciales desleales de las empresas en sus relaciones con los consumidores en el mercado interior. 
hacer efectivos de forma sumaria y expeditiva los créditos derivados de la actuación profesional en un determinado proceso» ${ }^{29}$. A pesar de no ser la única vía que tienen los abogados para reclamar sus honorarios, dado que también pueden acudir a un procedimiento declarativo o bien a un proceso monitorio, permite a procuradores y abogados obtener un título ejecutivo para la reclamación de sus honorarios que les permite el cobro inmediato de los mismos, siempre que aporten documentos que demuestren fehacientemente la procedencia y la cuantía de los honorarios o derechos impagados.

Cabe recordar que la reforma de la Ley de Enjuiciamiento Civil (LEC) operada por la Ley $13 / 2009^{30}$ para la implantación de la nueva oficina judicial (LINOJ), amplió notoriamente las competencias y funciones de los secretarios judiciales ${ }^{31}$; desde entonces, los expedientes de jura de cuentas deben sustanciarse ante el secretario judicial del órgano jurisdiccional que hubiera conocido del procedimiento en el que el abogado actuó por cuenta del cliente, de manera que desaparece por completo la intervención judicial ${ }^{32}$.

29 TC (Pleno), Sentencia 110/1993, de 25 de marzo de 1993.

30 Ley 13/2009, de 3 noviembre de 2009 de reforma de la legislación procesal para la implantación de la nueva oficina judicial (BOE núm. 266, de 4 de noviembre de 2009), reformada con posterioridad al planteamiento de la cuestión prejudicial comentada por la Ley 42/2015, de 5 de octubre, de reforma de la Ley 1/2000, de 7 de enero de 2000, de enjuiciamiento civil (BOE núm. 239, de 6 de octubre de 2015).

31 A partir de la misma reforma, los secretarios judiciales son competentes para tramitar y, en su caso, resolver los procedimientos monitorios, de manera que cuando el deudor no atienda el requerimiento de pago o no comparezca ante el tribunal corresponde al secretario judicial dictar un decreto dando por terminado el proceso monitorio, dotado de fuerza de cosa juzgada. El TJUE declaró en su Sentencia de 14 de junio de 2012, Banco Español de Crédito, C-618/10, ECLI:EU:C:2012:349, que la normativa española no era acorde con las directivas en materia de protección de los consumidores, al no permitir que el juez que conoce una demanda en un proceso monitorio examine de oficio el carácter abusivo de una cláusula sobre intereses de demora contenida en un contrato. Asimismo, en la Sentencia de 18 de febrero de 2016, Finanmadrid EFC SA, C-49/14, ECLI:EU:C:2016:98, posterior al planteamiento de la cuestión prejudicial que nos ocupa, el TJUE volvió a recordar que la Directiva 93/13 se oponía a una normativa nacional que no permitiera al juez que conoce de la ejecución de un requerimiento de pago apreciar de oficio el carácter abusivo de una cláusula contenida en un contrato celebrado entre un profesional y un consumidor, cuando la autoridad que conoció de la petición de juicio monitorio (el secretario judicial) carece de competencia para realizar tal apreciación.

32 Como señalara SÁNCHEZ LÓPEZ, la LINOJ «ha sustraído al Tribunal y traspasado al secretario judicial, la competencia para examinar la solicitud del procurador o del abogado y admitirla a trámite dirigiendo al deudor el requerimiento de pago frente al 
La nueva redacción de los arts. 34 y 35 de la LEC $^{33}$ dispone que si el cliente frente al que se reclama la deuda no formula oposición, el procedimiento se desarrolla de manera definitiva sin debate contradictorio respecto al fondo. $\mathrm{Si}$, por el contrario, el cliente se opone a la reclamación por considerarlos indebidos, el secretario judicial entra a examinar la cuenta, las actuaciones procesales y la documentación aportada y determina mediante decreto la cantidad a satisfacer por el cliente. Del mismo modo, si no existe presupuesto previo aceptado por ambas partes y el cliente impugna la cuantía de los honorarios por considerarla excesiva, el secretario judicial procede, en este caso, a su regulación conforme al procedimiento de tasación de costas dispuesto en los arts. 241 y siguientes de la LEC. Así, el expediente de jura se sustancia con un título ejecutivo y no comporta debate contradictorio en cuanto al fondo, siempre que el deudor no lo desencadene formulando oposición, de manera que los deudores quedan obligados a satisfacer la cantidad que hayan determinado los secretarios judiciales, bajo apercibimiento de apremio.

Basándose en ello, el secretario judicial del Juzgado de Violencia sobre la Mujer de Terrassa, competente para conocer sobre la reclamación presentada por el Sr. Margarit Panicello, albergaba dudas sobre la compatibilidad del procedimiento de jura de cuentas con las directivas relativas a la protección de los consumidores, ya que dicho procedimiento no le permite examinar de oficio la existencia de cláusulas abusivas o prácticas comerciales desleales en los contratos celebrados entre abogados y representados, por lo que decidió suspender el procedimiento y plantear al TJUE varias cuestiones prejudiciales ${ }^{34}$.

que caben alegaciones relativas a su carácter indebido o excesivo, así como a resolver todo ello mediante decreto en el que fijará la cantidad debida por tales conceptos, bajo apercibimiento de apremio» (Bárbara SÁNCHEZ LÓPEZ, "Reformas del Libro I de la LEC sobre disposiciones generales relativas a los juicios civiles (I): arts. 1 a 128 LEC» en Julio BANACLOCHE PALAO (coord.), Guía práctica de la nueva oficina judicial, La Ley, Madrid, 2010, p.141).

Ley 1/2000, de 7 de enero de 2000, de Enjuiciamiento Civil.

34 En concreto, las cuestiones eran las siguientes: «1) ¿Se oponen los arts. 34, 35, 207, apdos. 2 a 4, de la [LEC,] al regular el procedimiento gubernativo de jura de cuentas, al art. 47 de la Carta de los Derechos Fundamentales de la Unión Europea por cuanto se veda la posibilidad de control judicial? En caso de resultar afirmativo: ¿Es el Secretario Judicial, en el ámbito del procedimiento de los arts. 34 y 35 de la [LEC], 'órgano jurisdiccional', a los efectos del art. 267 del Tratado de Funcionamiento de la Unión Europea? 2) ¿Se oponen los arts. 34 y 35 de la [LEC] a los arts. 6, apdo. 1, y 7 , apdo. 2, de la Directiva [93/13] y a los arts. 6, apdo. 1, letra d), 11 y 12 de la Directiva [2005/29], al vedar el control de oficio de las eventuales cláusulas abusivas o prácticas comerciales desleales que contengan los contratos celebrados entre abogados 


\section{EN EL ÁMBITO DEL PROCEDIMIENTO DE LA JURA DE CUENTAS ¿̇EL SECRETARIO JUDICIAL ES UN «ÓRGANO JURISDICCIONAL»?}

En la segunda parte de su primera cuestión, el propio secretario judicial pregunta si en el ámbito del procedimiento de los arts. 34 y 35 LEC constituye un «órgano jurisdiccional» a efectos del art. 267 TFUE. En este sentido, tiene interés destacar que a pesar de que el secretario judicial comienza su escrito de planteamiento afirmando que reúne los requisitos enumerados en la jurisprudencia del TJUE para ser considerado órgano jurisdiccional a los efectos del art. 267 TFUE, al mismo tiempo parece poner en duda su propia competencia, pues traslada una serie de argumentos contrarios a la misma.

Por un lado, trae a colación una serie de pronunciamientos judiciales que no ayudan a avalar su competencia prejudicial, como son la sentencia de 28 de septiembre del Tribunal de Conflictos de Jurisdicción ${ }^{35}$, en la cual señala que «el expediente de jura de cuentas no solo ha perdido su carácter jurisdiccional tras la Ley Orgánica 13/2009, sino que incluso podría ser regulado fuera de las leyes procesales», o el auto 163/2013 de 9 de septiembre del TC, en el que este concluye que a efectos de la normativa que rige los procedimientos seguidos ante el TC, las resoluciones dictadas por los secretarios judiciales no deben considerarse actos judiciales ${ }^{36}$.

Por otro lado, a pesar de mostrar su preocupación por verse obligado a requerir el pago de una cuantía relativamente elevada a un consumidor o usuario sin que se le permita controlar de oficio la eventual existencia de cláusulas abusivas o incluso un comportamiento abusivo o desleal por parte del letrado, señala en su escrito que «quizá» pueda interpretarse que el «juez» competente para asegurar la tutela judicial efectiva de los clientes, sea el «órgano

[y] personas físicas que actúan con un propósito ajeno a su actividad profesional? 3) ¿Se oponen los arts. 34 y 35 de la [LEC] a los arts. 6, apdo. 1, 7, apdo. 2, y [punto 1, letra q) del anexo] de la Directiva [93/13], al impedir la práctica de prueba en el procedimiento administrativo de 'jura de cuentas' para resolver la cuestión?». Tribunal de Conflictos de Jurisdicción, sentencia 4/2011, de 28 de septiembre.

36 Como consecuencia del amparo interpuesto contra un decreto de un secretario judicial dictado en un procedimiento abreviado, por considerar vulnerado el derecho a un proceso sin dilaciones, el TC decidió a través de este auto elevar al Pleno del TC una cuestión interna de inconstitucionalidad respecto del art. 102 bis, apdo. 2, de la Ley 29/1998, de 13 de julio, reguladora de la jurisdicción contencioso-administrativa, en la redacción dada al mismo por la Ley 13/2009, de 3 de noviembre, de reforma de la legislación procesal para la implantación de la nueva Oficina judicial, por oposición al art. 24.1 CE. 
jurisdiccional» que conocerá del posible procedimiento declarativo ulterior que puedan iniciar las partes ${ }^{37}$.

Así, esta cuestión se convierte en preliminar y sobre ella van a pronunciarse de manera diversa tanto España y la Comisión en sus observaciones como la abogada general y el TJUE.

\section{LA POSICIÓN DEL ESTADO ESPAÑOL: UNA NEGATIVA FIRME}

Como hiciera en el asunto Consorci Sanitari del Maresme respecto al Tribunal Català de Contractes del Sector Públic, en su escrito de observaciones $^{38}$ el Estado español manifiesta de manera clara su disconformidad con el reconocimiento de competencia prejudicial a los secretarios judiciales en el expediente de jura de cuentas.

Como argumento de base, España considera que la jura de cuentas constituye un simple incidente ${ }^{39}$ en el marco de un procedimiento principal y por ello descarta de manera rotunda que los secretarios judiciales ejerzan competencia jurisdiccional alguna. Sostiene además el carácter no jurisdiccional de las resoluciones de los secretarios judiciales ${ }^{40}$, defendiendo que los decretos que ponen fin a la jura de cuentas son resoluciones procesales que no resuelven ninguna controversia y carecen de efectos de cosa juzgada. Por un lado, niega el efecto de cosa juzgada material, recordando que los arts. 34 y 35 LEC establecen que el decreto que pone fin a la jura de cuentas «no prejuzgarán, ni siquiera parcialmente, la sentencia que pudiere recaer en juicio ordinario ulterior». Por otro lado, a pesar de que los citados artículos también dispongan que el decreto «no será susceptible de recurso» y de que con posterioridad pueda iniciarse su correspondiente procedimiento de ejecución, nuestro país alega que el decreto del secretario judicial no constituye por sí solo un título ejecutivo sino que dicha ejecución se fundamentaría en la minuta o cuenta emitida por el abogado que iría acompañada de una resolución procesal (no judicial) y en base a ello niega que las resoluciones de los secretarios judiciales

37 Fundamento segundo del decreto de planteamiento.

38 Escrito de observaciones formuladas por María José García-Valdecasas Dorrego en nombre del Estado español como parte interviniente, presentadas el 12 de enero de 2016, inscritas en el registro del TJUE el 13 de enero de 2016, con número de registro 1010012.

39 Apdo. 61 de sus observaciones.

40 Apdos. 75 a 85 de sus observaciones. 
produzcan efecto de cosa juzgada formal, esto es, la imposibilidad de que una determinada decisión sea recurrida ${ }^{41}$.

Otro de los fundamentos que utiliza el Estado español para negar el carácter jurisdiccional de los secretarios judiciales en este tipo de procedimientos es su falta de independencia, afirmando que los secretarios no cumplen con el elemento externo de la independencia, es decir, el ejercicio de sus funciones con plena autonomía ${ }^{42}$. Para ello se basa en que el art. 452 LOPJ dispone que los secretarios judiciales ejercerán sus funciones con sujeción al principio «de autonomía e independencia en el ejercicio de la fe pública judicial» y «al de unidad de actuación y dependencia jerárquica» en todas las demás que se les encomienden. En este sentido, a pesar de que señala en sus alegaciones que la función del secretario está más próxima a la de dar fe de que las actuaciones alegadas por los letrados en su cuenta o minuta han tenido efectivamente lugar, que a la de aplicar normas jurídicas, considera que «no puede concluirse que los secretarios judiciales en las funciones que tienen atribuidas en la jura de cuentas, cumplan el requisito relativo a la independencia ${ }^{43}$.

\section{LA COMISIÓN, A FAVOR DE LA ADMISIÓN}

En contraposición a la postura defendida por España, la Comisión entiende que a pesar de que los secretarios judiciales no formen parte del Poder Judicial español, cuando estos actúan en el marco del art. 35 LEC lo hacen como órgano jurisdiccional en el sentido del art. 267 TFUE y, por ello, propone al TJUE que admita el planteamiento y se declare competente para su conocimiento $^{44}$.

De una parte, considera que los decretos constituyen decisiones obligatorias ya que en ciertos momentos del procedimiento de la jura de cuentas los secretarios judiciales requieren al deudor de pago bajo apercibimiento: «La decisión del secretario, o su primer requerimiento en caso de no oposición, puede ejecutarse por un juez en el marco de un procedimiento de ejecución forzosa $»^{45}$. De otra, estima que "el hecho de que pueda iniciarse un procedimiento declarativo ulterior, autónomo, por parte del abogado o de su cliente,

41 España considera que el decreto únicamente despliega los efectos de fijar la cantidad debida.

42 Apdos. 69 a 72 de sus observaciones.

43 Apdo. 73 de sus observaciones.

44 Apdo. 18 del escrito de observaciones formuladas por Julio Baquero Cruz en nombre de la Comisión como parte interviniente, presentadas el 18 de diciembre de 2015, inscritas en el registro del TJUE el 21 de diciembre de 2015, con el número 1009153.

45 Apdo. 25 de sus observaciones. 
no priva a esta decisión de carácter obligatorio ni de su naturaleza jurisdiccional ${ }^{46}$.

Finalmente, en cuanto a la independencia e imparcialidad de los secretarios judiciales, la Comisión entiende que los secretarios se encuentran suficientemente protegidos frente a posibles injerencias o presiones externas o internas; al respecto, además de mencionar el art. 452 LOPJ, añade que los arts. 16, letra h), y 21, número 2) del Reglamento Orgánico del Cuerpo de Secretarios Judiciales ${ }^{47}$ disponen que los superiores jerárquicos de los secretarios judiciales no pueden impartir instrucciones particulares sobre asuntos concretos pendientes en los que los secretarios intervengan en calidad de fedatarios o en el ejercicio de sus competencias de ordenación y dirección del proceso y señala que a pesar de que en tales disposiciones no se menciona la competencia relativa a las reclamaciones de honorarios de abogado, seguramente es «porque cuando se adoptó esa disposición aún no se les había atribuido tal competencia ${ }^{48}$.

De este modo, para la Comisión, cuando el secretario judicial conoce de la jura de cuentas, debe ajustarse exclusivamente a los dispuesto en la propia LEC, es decir, al principio de legalidad, y goza, por tanto, «de una independencia que no puede verse afectada por el Ministerio de Justicia al que están adscritos $»^{49}$.

\section{LA DECLARACIÓN DE INCOMPETENCIA POR PARTE DEL TRIBUNAL}

Como es habitual cuando el Tribunal tiene que valorar la condición de órgano jurisdiccional nacional, en la sentencia objeto de este comentario el TJUE se centra en los requisitos que considera pertinentes, que en esta ocasión resultan ser el carácter obligatorio de la jurisdicción, el ejercicio de funciones jurisdiccionales y la independencia del órgano.

Respecto al carácter obligatorio de la jurisdicción, el TJUE considera que la competencia de los secretarios judiciales para tramitar el expediente de jura de cuentas es de carácter puramente incidental y facultativo, ya que para obtener el cobro de sus honorarios el abogado no está obligado a utilizar la

46 Ibid.

47 Real Decreto 1608/2005, de 30 de diciembre, por el que se aprueba el Reglamento Orgánico del Cuerpo de Secretarios Judiciales (BOE núm. 17, de 20 de enero de 2006).

48 Apdo. 32 de sus observaciones.

49 Apdo. 33 de sus observaciones. 
jura de cuentas, sino que puede optar libremente entre este procedimiento y el proceso declarativo ordinario o el procedimiento monitorio.

El TJUE reconoce que se ha pronunciado en determinadas circunstancias sobre cuestiones prejudiciales que le habían planteado órganos remitentes cuya competencia, pese a tener carácter facultativo, no dependía de un acuerdo entre las partes y cuyas resoluciones eran vinculantes para estas, como sucede precisamente en el caso de los secretarios judiciales en el marco de los expedientes de jura de cuentas. Sin embargo, advierte de que tales órganos ejercían sus funciones en el marco de procedimientos que tenían carácter plenamente jurisdiccional ${ }^{50}$, lo que a su juicio no sucede en el caso del expediente de jura de cuentas, que según él se sitúa al margen del sistema jurisdiccional nacional por dos razones: de un lado, porque la incoación del procedimiento no impide que un tribunal ordinario sustancie autónomamente un proceso declarativo o un procedimiento monitorio ni constituye una causa de inadmisibilidad de los motivos que pudieran formularse ante dicho tribunal; de otro, porque el TJUE considera que los decretos dictados por los secretarios judiciales son similares a las resoluciones de carácter administrativo, debido a que aun siendo firmes e inmediatamente ejecutivos, sin que se admita recurso alguno contra ellos ${ }^{51}$, no gozan de los atributos de una resolución judicial, especialmente de la fuerza de cosa juzgada material ${ }^{52}$.

50 Auto de 13 de febrero de 2014, Merck Canada, C-555/13, EU:C:2014:92, apdo. 18; Sentencia de 12 de junio de 2014, Ascendi Beiras Litoral e Alta, auto Estradas das Beiras Litoral e Alta, C-377/13, EU:C:2014:1754, apdo. 28, y sentencia de 6 de octubre de 2015, Consorci Sanitari del Maresme, C-203/14, EU:C:2015:664, apdo. 23.

51 Trayendo a colación la Sentencia de la Sala de lo Contencioso-Administrativo del Tribunal Superior de Justicia de Andalucía (sede de Granada, Sección 1a) de 14 de diciembre de 2012, rollo de apelación 632/2012, el secretario judicial señalaba en su escrito de planteamiento que los procedimientos declarativos que puedan plantearse posteriormente "no constituyen en sí un recurso contra el Decreto dictado por el secretario judicial» ya que el posible procedimiento ordinario posterior se manifestaría como un procedimiento nuevo, lo que vendría por tanto a justificar la necesidad del reenvío prejudicial.

52 La ausencia de este efecto goza de reconocimiento general. Como señala MARTÍN CONTRERAS, «es unánime la doctrina al establecer que el procedimiento sumario de cuentas del abogado no produce efectos de cosa juzgada material, de manera que, una vez agotada la vía excepcional de la jura de cuentas, cualquiera de las partes en el citado procedimiento podrá acudir al procedimiento declarativo ordinario» (Luis MARTÍN CONTRERAS, Las costas procesales, Bosch, Barcelona, 2015, p. 556). 
No había sido de esta opinión la abogada general, para quien el hecho de que una reclamación contenciosa de honorarios pudiera ser objeto a la vez de un expediente de jura de cuentas y de un procedimiento ordinario, sin que existiera por tanto litispendencia, no puede ser argumento para negar en dicho expediente a los secretarios judiciales la condición de órgano jurisdiccional ya que de lo contrario, también debería ponerse en tela de juicio la condición de órgano jurisdiccional de los tribunales ordinarios que conocen de la reclamación contenciosa en paralelo a los secretarios judiciales.

En cuanto al segundo argumento del TJUE, la abogada general consideraba que la falta de fuerza de cosa juzgada material no resta carácter jurisdiccional a las resoluciones dictadas en la jura de cuentas ya que con independencia de que con posterioridad puedan impugnarse en un procedimiento separado, las resoluciones de los secretarios judiciales tienen para las partes del expediente los mismos efectos que las resoluciones judiciales ${ }^{53}$. La abogada general señala que dichas resoluciones sí tienen fuerza de cosa juzgada formal y en ellas se basan, bien un requerimiento de pago al deudor, que tiene un carácter ejecutivo autónomo, bien, en su caso, la obligación para el acreedor, vinculante por sí misma, de aceptar una reducción de sus honorarios ${ }^{54}$.

53 Sobre este mismo extremo, como ya lo hiciera CARRERA HERNÁNDEZ, cabe recordar que el Tribunal Supremo, en su sentencia de 19 de junio de 2008 (Sala Primera de lo Civil, Sentencia núm. 611/2008) señaló que a pesar de que las decisiones de los secretarios judiciales sean revisables en un declarativo ordinario posterior y carezcan, por tanto, de plena eficacia de cosa juzgada material, los decretos son revisables solo respecto de aquello que no pudo formularse en el procedimiento ante el secretario judicial ya que el abogado no puede acudir al juicio ordinario «con la finalidad de que se estime en su integridad la cuantía de la minuta — reclamando la diferencia entre lo que considera debido y lo reconocido en el expediente de jura de cuentas- y solo porque no le convence el argumento empleado entonces por el Tribunal para rebajar los honorarios (F. Jesús CARRERA HERNÁNDEZ, "¿Son los secretarios judiciales órganos jurisdiccionales a los efectos del planteamiento de cuestiones prejudiciales ante el Tribunal de Justicia?», Revista General de Derecho Europeo, núm. 38, 2016, p. 200).

54 Para la abogada general es el efecto de cosa juzgada formal y el carácter ejecutivo de los decretos de los secretarios judiciales lo que hacen que dichos decretos sean diferentes a otras resoluciones que han sido objeto de peticiones de decisión prejudicial y cuya falta de fuerza de cosa juzgada contribuyó a que se decidiera no reconocer la condición de órgano jurisdiccional al remitente. Para ello recuerda la Sentencia de 19 de diciembre de 2012, Epitropos tou Elegktikou Synedriou, C-363/11, EU:C:2012:825, y la Sentencia de 17 de julio de 2014, Emmeci, C-427/13, EU:C:2014:2121, en las que 
A mayor abundamiento, la abogada general considera que los decretos de los secretarios judiciales muestran cierto paralelismo con las resoluciones dictadas en procedimientos de medidas provisionales que también adquieren de inmediato carácter ejecutivo, sin prejuzgar por ello la resolución que pueda recaer posteriormente en un procedimiento principal.

En este sentido, cabe recordar que el TJUE se ha pronunciado sobre cuestiones prejudiciales planteadas por órganos jurisdiccionales que estaban conociendo de procedimientos sumarios y cuyas resoluciones carecían de fuerza de cosa juzgada ${ }^{55}$. Ejemplo de ello es la sentencia Hoffman-La Roche, ${ }^{56}$ en la que el TJUE examinaba la cuestión prejudicial planteada por el OLG de Karlsruhe, que analizaba la oportunidad de conceder una medida provisional en el marco de una apelación contra una resolución emanada por el Landgericht de Friburgo. En dicho pronunciamiento, el TJUE consideró que el hecho de que dichas resoluciones no tuvieran efecto de cosa juzgada y que, por tanto, existiera la posibilidad de iniciar un procedimiento posterior en términos idénticos, no le impedía considerar que dicho órgano actuaba válidamente con arreglo al actual art. 267 TFUE.

El TJUE cierra sus fundamentos respecto al carácter jurisdiccional de las funciones del secretario judicial trayendo a colación una sentencia del $\mathrm{TC}^{57}$ para considerar con base en la misma que el expediente de jura de cuentas constituye un procedimiento de carácter administrativo, en el marco del cual no puede considerarse que los secretarios judiciales ejerzan funciones jurisdiccionales $^{58}$. Esta argumentación no deja de sorprender si tenemos en cuenta

las resoluciones de los órganos que realizaban el reenvío prejudicial tenían carácter de informe o de recomendación.

55 En este sentido, véase Mar JIMENO BULNES, La cuestión prejudicial del artículo 177 TCE, Bosch, Barcelona, 1996, pp. 286 a 288.

56 Sentencia de 24 de mayo de 1977, C-107/76, ECLI:EU:C:1977:89.

57 Se trata de la sentencia 58/2016, de 17 de marzo de 2016, que da respuesta a la cuestión interna de inconstitucionalidad planteada mediante el auto 163/2013 del TC, citado por el secretario judicial en su decreto de planteamiento (véase la nota 34 de este comentario). La sentencia declaró inconstitucional y nulo el primer párrafo del art. 102 bis, apdo. 2 de la ley de jurisdicción contencioso-administrativa, según el cual no cabía que el juez revisara los decretos dictados por el secretario judicial para resolver los recursos de reposición planteados contra sus propias decisiones, al considerar que la ausencia de revisión por un juez o tribunal de algunas de las decisiones que, tras la implantación de la nueva oficina judicial, recaían en exclusiva en los secretarios judiciales, lesionaba el derecho fundamental a la tutela judicial efectiva (art. 24.1 CE) y el principio de exclusividad de la potestad jurisdiccional (art. 117.3 CE).

Apdo. 35 de la Sentencia. 
que el TJUE ha declarado repetidamente ${ }^{59}$ que el concepto de «órgano jurisdiccional nacional» debe ser un concepto de contenido específicamente comunitario, no determinable, por tanto, por los Estados miembros ${ }^{60}$. Además, dicha sentencia se ocupaba exclusivamente de los recursos contra las resoluciones del secretario judicial en el proceso contencioso-administrativo y desde la estricta perspectiva del derecho a la tutela judicial efectiva, por lo que cabe albergar dudas sobre su pertinencia a los fines de decidir sobre la competencia prejudicial en el expediente de jura de cuentas ${ }^{61}$.

El TJUE entra a valorar, finalmente, la independencia de los secretarios judiciales cuando resuelven sobre las reclamaciones de honorarios de los letrados. Como bien es sabido, el concepto de independencia judicial entraña, según la jurisprudencia del TJUE, un aspecto externo y otro interno. El aspecto interno de la independencia se asocia al concepto de imparcialidad y se refiere a la equidistancia que debe guardar el órgano de que se trate con respecto a las partes del litigio y a sus intereses respectivos en relación con el objeto de ese litigio. A su vez, el aspecto externo de la independencia exige que la instancia que haya de resolver esté protegida de injerencias o presiones externas que

59 Así lo vuelve a recordar en el apdo. 27 de la Sentencia que nos ocupa.

60 Para CIENFUEGOS MATEO «esta noción no puede quedar abandonada completamente al albur del Derecho interno de cada uno de los países que integran la UE, pues se correría el riesgo de que sectores completos de la vida económica y social pudieran escapar, por voluntad de los Estados miembros, al control sobre el Derecho comunitario que lleva a cabo el Tribunal de Justicia a través del incidente prejudicial, comprometiéndose así la eficacia de este mecanismo de cooperación jurisdiccional» (Manuel CIENFUEGOS MATEO, "Juez nacional-Tribunal de Justicia: la cuestión prejudicial» en J. M. BENEYTO PÉREZ, Tratado de Derecho y Politicas de la Unión Europea, Sistema Jurisdiccional de la UE, tomo V, Aranzadi, Cizur Menor, 2012, p. 549).

61 En sus conclusiones, la abogada general señala que «si el remitente es o no 'órgano jurisdiccional' a los efectos del art. 267 TFUE es una cuestión que se ha de apreciar estrictamente desde la óptica del Derecho de la Unión. Por ello, no resulta decisivo que reciba una u otra consideración en el Derecho nacional. Lo mismo se puede decir de la apreciación que reciba la cuestión en la jurisprudencia nacional y, en el presente asunto, por igual motivo, de la jurisprudencia del TC mencionada por el Secretario Judicial y sobre la que se discutió en la vista, aun cuando dicha jurisprudencia indique que, a efectos de la normativa que rige los procedimientos seguidos ante el tribunal Constitucional español, una resolución dictada por el Secretario Judicial en otro procedimiento distinto del asunto principal no deba considerarse 'acto judicial'» (punto 63, la cursiva está en el original). 
puedan hacer peligrar la independencia de sus miembros en el enjuiciamiento de los litigios que se les sometan ${ }^{62}$.

En este sentido, el TJUE coincide con la abogada general y todas las partes intervinientes en que los secretarios judiciales cumplen plenamente con el aspecto interno de la independencia y desempeñan sus funciones con plena observancia de la imparcialidad y de la objetividad en relación con las partes y con los intereses de estas en el litigio, actuando, por tanto, como terceros. En cambio, no llega a la misma conclusión respecto a la dimensión externa.

Para la abogada general existen varias premisas que aseguran y demuestran la independencia externa de los secretarios judiciales, como son el hecho de que sean seleccionados a través de los sistemas de oposición o de concurso-oposición libre ${ }^{63}$ o el hecho de que los secretarios judiciales ostenten el derecho individual al mantenimiento de su condición funcionarial sin ser apartados del puesto de trabajo que desempeñen ${ }^{64}$ sino solo en los supuestos y condiciones establecidos legalmente ${ }^{65}$.

Por último, la abogada general considera que la competencia que corresponde a los secretarios judiciales en la jura de cuentas no es objeto de delegación ni habilitación y destaca que en cada procedimiento los secretarios judiciales actúan, exclusivamente, de conformidad con las competencias que les hayan sido atribuidas sin estar sujetos a indicaciones ${ }^{66}$, ya que la autoridad pública que los emplea no puede, en ningún caso, influir en procedimientos

62 El TJUE recuerda estas dos dimensiones en los apdos. 37 y 38 de la sentencia. Sobre el elemento de la independencia, véase Manuel CIENFUEGOS MATEO, «Independencia judicial y planteamiento de cuestiones prejudiciales. Comentario a la sentencia Syfait (C-53/03), de 31 de mayo de 2005, del Tribunal de Justicia», Revista General de Derecho Europeo, núm. 8, 2005.

63 Arts. 442 y 450 de la Ley Orgánica 6/1985, de 1 de julio, del Poder Judicial (en adelante LOPJ).

64 Apdo. 2 del art. 443 de la LOPJ.

65 La abogada general destaca también el de que la sanción disciplinaria de separación del servicio solo se les pueda imponer por condena penal o por las faltas muy graves que se recogen de manera exhaustiva y definen con suficiente exactitud en la ley (puntos 74 a 76 de sus conclusiones).

El art. 452 LOPJ, apdo. 1, dispone que «los secretarios judiciales desempeñarán sus funciones con sujeción al principio de legalidad e imparcialidad en todo caso, al de autonomía e independencia en el ejercicio de la fe pública judicial, así como al de unidad de actuación y dependencia jerárquica en todas las demás que les encomienden esta ley y las normas de procedimiento respectivo, así como su reglamento orgánico». 
pendientes ni impartir instrucciones particulares relativas a asuntos concre$\operatorname{tos}^{67}$.

En la vista, España sostuvo que las disposiciones que prohíben a la superioridad de los secretarios judiciales dar a estos instrucciones particulares relativas a asuntos concretos no se refieren a los expedientes de jura de cuentas ${ }^{68}$. Sin embargo, la abogada general rebate el argumento del Estado español y recuerda que el tenor de tales normas fue aprobado antes de que se les atribuyera la competencia sobre la jura de cuentas a los secretarios judiciales y que, por tanto, «no cabe duda de que el principio de libertad frente a indicaciones de que gozan en esos casos concretos se aplica también, por analogía, a las resoluciones que deben adoptar en la jura de cuentas ${ }^{69}$. Por ello, a pesar de que con carácter general estén sujetos a las indicaciones de su superioridad, la abogada general concluye que los secretarios judiciales son «indudablemente» ${ }^{70}$ independientes cuando desempeñan las funciones que tienen atribuidas en cada expediente concreto de jura de cuentas.

Por el contrario, el TJUE adopta el criterio seguido por el Estado español determinando que el secretario judicial, en el ejercicio de sus funciones, debe atenerse a las instrucciones que le imparta su superior jerárquico salvo cuando ejerce las competencias relativas a la fe pública judicial, ya que «en el estado actual de la legislación española, el secretario judicial tramita el expediente de jura de cuentas [...] con observancia de los principios de unidad de actuación y dependencia jerárquica $»^{71}$, no constituyendo un órgano jurisdiccional a efectos del art. 267 TFUE y careciendo, por tanto, de facultad para plantear una cuestión prejudicial.

Tras este pronunciamiento negativo, el TJUE apunta que deberá ser el juez de ejecución, competente para acordar el apremio sobre la cantidad determinada en el decreto, quien deba examinar el eventual carácter abusivo de una cláusula contractual que figure en el contrato celebrado entre un abogado y su cliente y quien podrá, en su caso, plantear al TJUE la petición de decisión prejudicial $^{72}$.

67 Arts. 16, letra h), y 21, punto 2, del Reglamento Orgánico, antes mencionado.

68 Así lo indica la abogada general en el punto 78 de sus conclusiones.

69 Ibid.

70 Ibid.

71 Lo que podría no cerrar las puertas a futuros planteamientos, en caso de que la legislación española se adaptase a los cambios competenciales de los secretarios judiciales.

72 Como señala CARRERA HERNÁNDEZ, el TJUE parece invitar «al cliente moroso para que continúe sin pagar su deuda tras la intervención del secretario judicial (F. Jesús CARRERA HERNÁNDEZ, «Los secretarios judiciales no son órganos jurisdiccionales a los efectos del planteamiento de cuestiones prejudiciales ante el Tribunal de 


\section{LAS DEMÁS CAUSAS DE INADMISIBILIDAD QUE NO SE PUDIERON ABORDAR}

Al declararse incompetente, el TJUE no aborda otras causas de inadmisibilidad relativas tanto a si el secretario judicial había proporcionado todos los elementos necesarios para que el TJUE se pronunciara ${ }^{73}$ como a si las cuestiones interpretativas formuladas eran decisivas para la resolución del procedimiento principal, lo que hubiera llevado a analizar el procedimiento de jura de cuentas a la luz de los derechos del consumidor protegidos por el derecho de la Unión y del derecho a la tutela judicial efectiva.

En cambio, la abogada general sí entra a analizar todas estas cuestiones. Por lo que se refiere a la suficiencia de elementos aportados, la abogada general coincide con la Comisión, considerando que «las explicaciones transmitidas por el Secretario Judicial sobre el marco de hecho y de Derecho del litigio principal son suficientes para que se dé una respuesta útil a las cuestiones prejudiciales planteadas $»^{74}$.

En cuanto a si la interpretación de las Directivas 93/13 y 2005/29 y del art. 47 de la Carta de Derechos Fundamentales eran decisivas para resolver el litigio principal, la abogada general consideraba que, según reiterada jurisprudencia, la Directiva 93/13 se aplica a las disposiciones legales que tienen por objeto regular las facultades que corresponden al juez nacional cuando este aprecia el carácter abusivo de las cláusulas contractuales. De esta forma, el expediente de jura de cuentas sí estaría comprendido en el ámbito de aplicación de esta directiva y, por lo tanto, la comprobación de oficio de si existen cláusulas abusivas, incumba a los secretarios judiciales o incumba posteriormente al juez o magistrado que vaya a conocer de la ejecución, es un extremo que puede tener su importancia para saber si la jura de cuentas es conforme con la Directiva 93/13. Al mismo tiempo, consideraba que la Directiva 2005/29 es aplicable antes, durante y después de una transacción comercial en relación con un servicio, ya que ateniéndose a la jurisprudencia dictada por el TJUE, debe considerarse que un contrato celebrado entre un abogado y su poderdante para la prestación de servicios jurídicos es, a efectos de la Directiva $2005 / 29$, una transacción comercial realizada en relación con un servicio y,

Justicia de la Unión Europea», Revista General de Derecho Europeo, núm. 42, 2017, p. 140).

73 En la vista, el Estado español añadió a sus objeciones la de que el secretario judicial no había aportado información suficiente sobre la configuración exacta de las cláusulas pactadas entre el abogado y su cliente. Así lo señala la abogada general en el punto 98 de sus conclusiones.

74 Punto 99 de las conclusiones. 
por lo tanto, si el secretario judicial constatara que el Sr. Margarit Panicello no había informado a su clienta sobre el precio de sus servicios ${ }^{75}$ y ello hiciera que esta tomara una decisión sobre esa transacción que de otro modo no hubiera tomado, la omisión de la información relativa al precio debería calificarse, a los efectos de la Directiva 2005/29, de práctica comercial desleal ${ }^{76}$.

En cuanto a la necesidad de interpretación del art. 47 de la Carta, la abogada general recordaba que el TJUE tiene declarado que la obligación de los Estados miembros de garantizar la efectividad de los derechos que la Directiva 93/13 confiere a los justiciables frente a la aplicación de cláusulas abusivas implica una exigencia de tutela judicial, consagrada asimismo en el art. 47 de la Carta, que el juez nacional debe observar ${ }^{77}$.

\section{PARA CONCLUIR: EL CASUISMO CONTINÚA}

En esta sentencia, el TJUE parece adoptar una postura mucho más exigente que en pronunciamientos anteriores, optando por considerar el efecto de cosa juzgada material de las resoluciones de un órgano como elemento imprescindible para considerar que un procedimiento tiene carácter jurisdiccional. De este modo, el caso se inscribe en la línea restrictiva mantenida en ocasiones, pero no siempre, por el TJUE y confirma una vez más las advertencias de Dámaso Ruiz-Jarabo sobre el hecho de que en relación con la noción de órgano jurisdiccional estamos ante «una jurisprudencia [...] carente de la necesaria coherencia, con el déficit de seguridad jurídica que comporta [...] una jurisprudencia casuística, muy elástica ${ }^{78}$. En particular, en el caso que nos ocupa es difícil disipar la impresión de contradicción con algún caso previo relativo también a los secretarios judiciales ${ }^{79}$. Con todo, vaya en descargo del

75 Tal como expusiera el secretario judicial, en su decreto de remisión, no consta que el Sr. Margarit Panicello informara previamente a la Sra. Hernández Martínez del precio de sus servicios.

76 Puntos 106 a 111 de las conclusiones.

77 Puntos 115 y 116 de las conclusiones.

78 Conclusiones presentadas el 28 de junio de 2001 en el asunto De Coster, C-17/00, ECLI:EU:C:2001:366, punto 14.

79 CARRERA HERNÁNDEZ trae a colación la Sentencia de 18 de febrero de 2016, Finanmadrid EFC, C-49/14, EU:C:2016:98, en la que el TJUE consideró que las resoluciones de los secretarios judiciales tienen efectos análogos a los de una resolución judicial, con fuerza de cosa juzgada (F. Jesús CARRERA HERNÁNDEZ, «Los secretarios judiciales no son órganos jurisdiccionales a los efectos del planteamiento 
TJUE la consideración de que la nueva regulación de las competencias de esta figura y su deslinde respecto de las de los jueces puede inducir a confusión.

Desde otra perspectiva, resulta llamativo que España se niegue de manera tan rotunda a que las dudas planteadas por el secretario judicial sean resueltas por el TJUE, más aún cuando a efectos del art. 267 TFUE la condición de «órgano jurisdiccional» depende únicamente del derecho de la Unión y el reconocimiento de dicha competencia a los secretarios judiciales tendría, por tanto, nulos efectos para el ordenamiento español.

Como daño colateral, al negar el carácter de órgano jurisdiccional a los secretarios judiciales en el procedimiento de jura de cuentas, el TJUE ha perdido la oportunidad de seguir desarrollando su jurisprudencia en materia de los requisitos concretos que se han de cumplir para garantizar efectivamente, en los procedimientos nacionales ejecutivos o sumarios, aquellos derechos que para los consumidores se consagran en el derecho de la Unión. Máxime cuando tanto la Comisión como la abogada general ${ }^{80}$ manifestaron de manera clara que cabía albergar serias dudas sobre la compatibilidad del citado procedimiento con los derechos tutelados en las Directivas 93/13 y 2005/39.

de cuestiones prejudiciales ante el Tribunal de Justicia de la Unión Europea», op. cit., pp. 136 y 140).

80 La abogada general concluye que «la Directiva 93/13/CEE, en relación con la Directiva 2005/29/CE y con el art. 47 de la Carta, debe interpretarse en el sentido de que se opone a una normativa nacional en la que, como sucede con la controvertida en el procedimiento principal, los órganos encargados de instruir los procedimientos mediante los que se resuelve sobre las reclamaciones de honorarios (expedientes de jura de cuentas) no pueden comprobar de oficio si en el contrato celebrado entre un abogado y un consumidor existen cláusulas abusivas o si se han dado prácticas comerciales desleales» (punto 146 de las conclusiones). 